\title{
Risk factors for major leg amputation in patients treated endovascularly due to critical limb ischaemia
}

\author{
Agnieszka Hamera', Andrzej Olech', Klaudia Koza', Pawel Grzelazka', \\ Adrianna Trofimiuk', Wioletta Banas ${ }^{2}$, Karol Suppan ${ }^{2}$, Jacek Budzynski ${ }^{2,3}$ \\ 'Student Scientific Group, Chair and Clinic of Vascular and Internal Diseases, Faculty of Health Sciences, Ludwik Rydygier \\ Collegium Medicum in Bydgoszcz, Nicolaus Copernicus University in Torun, Poland \\ ${ }^{2}$ Clinic of Vascular and Internal Diseases, Jan Biziel University Hospital No. 2 in Bydgoszcz, Poland \\ ${ }^{3}$ Chair of Vascular and Internal Diseases, Faculty of Health Sciences, Ludwik Rydygier Collegium Medicum in Bydgoszcz, \\ Nicolaus Copernicus University in Torun, Poland
}

\begin{abstract}
Introduction. Critical limb ischaemia (CLI) is an advanced phase of chronic lower extremity ischaemia linked to increased mortality, decreased quality of life, and the risk of leg amputation.

The aim of this study was to determine factors affecting the risk of leg amputation among patients with CLI treated endovascularly as a first approach.

Material and methods. Of I 8 patients treated endovascularly, 32 (27\%) had a leg amputated. Their clinical data were analysed retrospectively.

Results. Patients who had a leg amputated initially had a higher Rutherford class, were older, and had a greater prevalence of comorbidities. In multivariate analysis, amputation-free survival was shortened by a history of dyslipidaemia, female gender, blood creatinine concentration, the need for target lesion revascularization, smoking habit, Rutherford class, and leukocyte blood count. Whereas, the factors which decreased the risk of leg amputation were: use of statins, the number of previous interventions, and blood LDL cholesterol concentration. Angiographic classification of lesion severity did not affect endovascular procedure outcome.

Conclusions. The risk of major amputation following endovascular treatment in patients with CLI was associated with a number of characteristics, mainly: atherosclerosis risk factors and necrosis advancement, and the number of reinterventions. To avoid endangering patients and the unnecessary utilization of resources, it would seem to be worth performing large studies to determine a risk stratification scoring system for patients with CLI, which could enable the qualification of risk-adjusted patients for endovascular or surgical revascularization or for primary leg amputation.
\end{abstract}

Key words: critical limb ischaemia, endovascular treatment, outcome, lower limb amputation risk factors

Acta Angiol 20I5; 2I , 4: I22-128

\section{Introduction}

Peripheral artery disease (PAD) has increased in the general population due to people living longer and an epidemic of diabetes and obesity. Critical limb ischaemia (CLI) is the advanced stage of lower limb ischaemia (LLI), whose incidence in Western countries is estimated as being $220-1,000$ new cases annually per million people [ $\mathrm{I}-3]$. CLI appears in $\mathrm{I}-3 \%$ of newly diagnosed cases of $\mathrm{LLI}$ and in $5-10 \%$ of patients initially

Address for correspondence: Jacek Budzynski, Chair of Vascular and Internal Diseases, Faculty of Health Sciences,

Ludwik Rydygier Collegium Medicum in Bydgoszcz, Nicolaus Copernicus University in Toruń, Poland, e-mail: budz@cps.pl 
diagnosed with intermittent claudication during 5 years of observation [I]. CLI is linked to an approximately $25 \%$ annual risk of cardiovascular death, and a $30 \%$ probability of major amputation [ 1,2$]$. In a recent study by Kay et al. [4], among individuals with intermittent claudication, I- and 3-year survival was respectively $98 \%$ and $96 \%$, and in the CLI group, I- and 3-year survival was respectively $74 \%$ and $51 \%$. In a study by Soga et al. [5], 4 I \% of patients with CLI died over the course of 2 years, of which $47 \%$ died due to cardiovascular causes. In another summarization, a 5-year mortality rate of $70 \%$ was reported for patients with CLI, which meant that the number of deaths attributed to CLI was higher than the sum total of deaths due to coronary artery disease (CAD), breast cancer and colorectal cancer over the same period [6]. The large number of deaths among patients with CLI resulted, at least partially, from the perioperative mortality rate related to limb amputation, which ranges from $2.8 \%$ to $30 \%$ of hospital deaths, with $2.2 \%$ of deaths occurring within 30 days and $45 \%$ within 12 months [7]. These percentages would be more terrifying considering that in the US approximately 65-75 thousand major amputations (above and below the knee) are performed annually due to CLI [6]. The annual direct cost of CLI treatment in the US exceeds $\$ 25$ billion. With obvious consequences of lower limb amputation one should also add the costs prosthetic, orthopaedic, rehabilitation and work absence.

The above-mentioned data show that CLI is a significant and resource-demanding problem. Intensive care is required for this clinical condition and consists of optimal medical treatment, physiotherapy, and endovascular and surgical treatment [I-3, 8-I I]. As the number of CLI patients treated percutaneously is increasing, it is important to be able to identify which patients are at greater risk of treatment failure, in order to allocate appropriately more intensive surveillance, aggressive or experimental treatment, or primary amputation for patients when the risk of treatment failure is high. Such CLI patient management might help avoid endangering patients and the unnecessary utilization of resources.

The aim of this study was to determine the factors affecting the risk of leg amputation among patients with CLI treated endovascularly as a first approach.

\section{Material and methods}

Between I January 2012 and 3 I December 2014 in our clinic 39 major lower limb amputations of 37 limbs due to CLI were performed. CLI was defined as completing criteria of class IV-VI by Rutherford classification [I]. In 7 (18\%) patients leg amputation was performed as a primary procedure (without previous endovascular treatment), and in 32 patients (82\%) who were treated earlier endovascularly as a first approach due to CLI were retrospectively analysed. These 32 patients were further analysed as an investigated group. As a control group acted all consecutive 86 patients treated in our centre endovascularly due to CLI between I March 20II and 3I December 20I4, who had at least one ambulatory visit in 2015 , but in whom leg amputation was not done. The date of the earliest endovascular procedure in group of patients with leg amputation was I March 20 I I. Demographic, clinical, biochemical and angiographic parameters of patients with leg amputation and with leg salvage were analysed and compared.

\section{Measured outcomes}

During the period between the performance of a percutaneous procedure and 31 August 20 I5, the target limb amputation (TLA) prevalence was measured. TLA was defined as the minor or major amputation of a previously stented limb during the follow-up period.

\section{Bioethics}

We were given permission to conduct the analysis by the local Bioethical Commission on 18 February 2014 (KB 139/2014) in accordance with an annex on 21 April 20I5. The study was conducted in accordance with the Revised Declaration of Helsinki.

\section{Statistics}

Statistical analysis was performed using STATISTICA software for Windows 10.0 (StatSoft, Inc. 20II, STATISTICA, data analysis software system, version 10). The results are expressed as mean \pm standard deviation. The following non-parametric tests were used to compare the values between the groups due to the inability to refute the hypothesis that the data were not normally distributed (Shapiro-Wilk test): the Mann-Whitney $U$ test and Fisher's exact test. The Spearman's rank correlations were also checked. The variables determining the length of time between the first revascularization procedure and amputation were analysed using progressive stepwise regression. The association between the respective factors and TLA occurrence was verified using survival analysis, the Cox's F test, and the log-rank test as a part of the Kaplan-Meier method. Cox's proportional-hazards regression analysis models were created to identify predictors of clinical outcomes. The statistical significance level was set at a P-value of $<0.05$.

\section{Results}

In our study, we analysed the data for 118 patients treated endovascularly as a first approach due to CLI. 


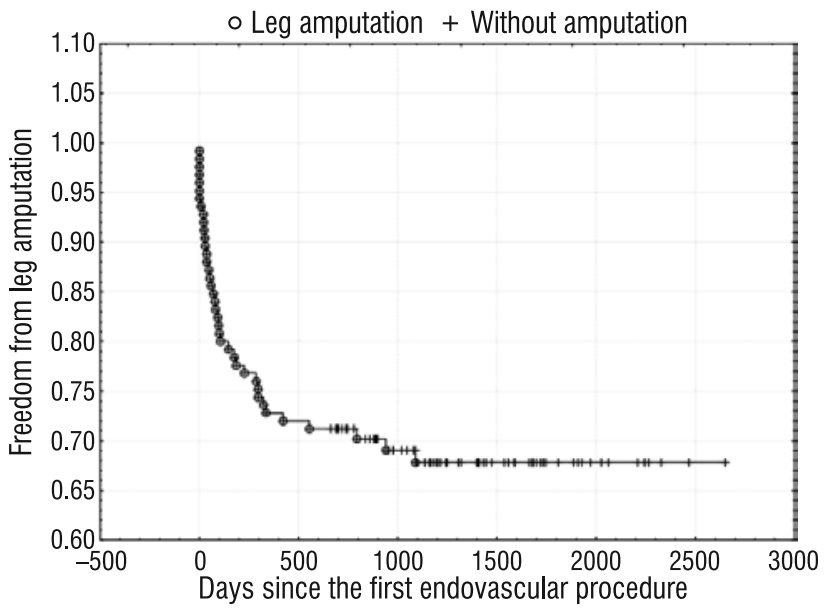

Figure I. Kaplan-Meier curve showing the risk of leg amputation in the analysed group

In $32(27 \%)$ of these patients, elective leg amputation due to unacceptable resting pain, necrosis and/or infection was undergone. The mean observation time between the first endovascular intervention and leg amputation in the 32 patients amounted to $220 \pm 257$ days ( $95 \%$ confidence interval [Cl]: |22-319 days; median \pm lower and upper quartile: $99 \pm 42.5-295$ days), and the mean observation time of the 86 patients in whom lower limb amputation was not performed amounted to $1310 \pm$ 506 days ( $95 \% \mathrm{Cl}$ : I,20 I-I ,4 I 8.5 days; median \pm lower and upper quartile: I, I $98 \pm 885-1,697$ days) (Fig. I). In all patients only bare metal self-expanding stents were implanted (Tab. I).

A comparison of demographic and clinical data at the date of the endovascular procedure between patients in whom lower limb amputation was performed and in individuals with a successful outcome to their endovascular procedure is presented in Table I. Patients with a leg amputation initially had the following: a higher class of Rutherford classification [I]; were older, with a greater prevalence of comorbidities, such as: chronic cardiac failure, diabetes mellitus, and chronic kidney disease; had greater blood levels of glucose and creatinine; a greater international normalized ratio (INR); as well as a higher leukocyte and platelet count (Tab. I). They also appeared to have more advanced target lesions according to the Trans-Atlantic Inter-Society Consensus (TASC) classification; the target lesion more frequently concerned arteries below the knee (BTK); and more frequently had at least two endovascular interventions performed (with at least one reintervention for target lesion revascularization [TLR]), defined as repeat percutaneous (endovascular) revascularization for a lesion anywhere within the stent or the $5 \mathrm{~mm}$ border proximal or distal to the stent due to symptom recurrence and target lesion occlusion (mainly due to in-stent restenosis, IRS) [12]. However, in patients with a leg amputation, percutaneous procedures were performed more frequently in those without stent implantation. Patients with a leg amputation also had a lower number of stents but the sum of their stent lengths was greater (Tab. I).

In multivariate analysis (Tab. 2), the risk of leg amputation was significantly increased and amputation-free survival was shortened by (in order of hazard ratio [HR] value): history of dyslipidaemia, female gender, creatinine blood concentration (even in the normal range), history of TLR, smoking habit, Rutherford class, and leukocyte blood count. Whereas, the factors which decreased the risk of leg amputation were (in order starting with the lowest HR): statins use (decreased risk by 14 times), number of previous interventions, and LDL blood concentration (Tab. 2). It was interesting that age and advancement in angiographic severity of treated lesions classified according to TASC $[1,8]$ had no significant influence on the duration of the amputation-free period (Tab. 2). The short amputation-free survival shown for the least advanced lesions (TASC A) at the femoropopliteal vascular level (Fig. 2) should be recognized as bias, because this was related to the coexistence of more advanced lesions in the BTK region (the lack of the main calf vessels is more advanced than TASC D for infrapopliteal lesions [8]). Diabetes mellitus, generally recognized as the strongest risk factor for lower limb amputation $[1,8,9]$, was significant only in the univariate Kaplan-Meier survival analysis (Fig. 3).

\section{Discussion}

In our study, we tried to determine the risk factors for lower extremity amputation after endovascular intervention had been used as the first approach. Such management of $C L I$ is widely accepted $[1,8,13,14]$. We analysed the importance of demographic, clinical, biochemical, angiographic and periprocedural factors, in univariate, multivariate and survival analysis (Tab. I, 2, Fig. I-3). We found that the strongest risk factor for leg amputation was history of dyslipidaemia (Tab. 2). In our study, the diagnosis of dyslipidaemia was based on medical history, in which the patient had reported previously elevated blood cholesterol and/or triglyceride concentration, independently of the current blood lipid level, and whether the patient had a history of hypolipidaemic drug use. In this sense, "dyslipidaemia" should be recognized as a long-acting factor, which begins its proatherogenic action in the patient's youth, and, according to the theory of cardiovascular continuum $[15,16]$, has stimulated atherogenesis for many years, rendering insufficient the pharmacological control 
Table I. Demographic and clinical data of the studied patients with $\mathrm{CLI}$ after endovascular treatment $(\mathrm{N}=1 \mathrm{I8})$

\begin{tabular}{|c|c|c|c|}
\hline Parameter & $\begin{array}{l}\text { Patients with leg amputation } \\
\qquad N=32(27 \%)\end{array}$ & $\begin{array}{l}\text { Patients without am putation } \\
\qquad N=86(73 \%)\end{array}$ & $\mathrm{p}$ \\
\hline Rutherford class & $5.0 \pm 0.7$ & $4.45 \pm 1.1$ & 0.01 \\
\hline Age (years) & $66.5 \pm 9.9$ & $63.0 \pm 9.0$ & 0.052 \\
\hline Male gender (N, \%) & $23(72 \%)$ & 70 (8।\%) & 0.26 \\
\hline History of CAD (N, \%) & $18(56 \%)$ & 35 (4I\%) & 0.64 \\
\hline History of stroke (N, \%) & $6(19 \%)$ & $8(9 \%)$ & 0.34 \\
\hline Diabetes mellitus ( $\mathrm{N}, \%)$ & $22(69 \%)$ & $24(28 \%)$ & 0.002 \\
\hline Hypertension (N, \%) & $29(9 \mid \%)$ & $60(70 \%)$ & 0.019 \\
\hline Smoking habit (N, \%) & $17(53 \%)$ & $44(51 \%)$ & 0.84 \\
\hline Dyslipidaemia (N, \%) & $22(69 \%)$ & $64(74 \%)$ & 0.044 \\
\hline LDL cholesterol [mg/dL] & $109.3 \pm 36.3$ & $126.7 \pm 37.5$ & 0.055 \\
\hline Triglycerides [mg/dL] & $121.5 \pm 42.4$ & $139.1 \pm 65.2$ & 0.234 \\
\hline Blood glucose [mg/dL] & $163.2 \pm 68.4$ & $107.1 \pm 28.9$ & 0.000 \\
\hline Leukocyte count [G/L] & $13.7 \pm 6.2$ & $8.9 \pm 2.4$ & 0.001 \\
\hline Blood platelets [G/L] & $356.4 \pm 143.5$ & $272.9 \pm 110$ & 0.001 \\
\hline INR & $1.14 \pm 0.2$ & $1.03 \pm 0.11$ & 0.003 \\
\hline aPTT (s) & $32.3 \pm 5.8$ & $31.2 \pm 4.8$ & 0.29 \\
\hline Smoking habit (N, \%) & $22(69 \%)$ & $44(51 \%)$ & 0.59 \\
\hline Creatinine $[\mathrm{mg} / \mathrm{dL}]$ & $1.47 \pm 0.87$ & $1.05 \pm 0.22$ & 0.001 \\
\hline Statins use (N, \%) & $28(88 \%)$ & $83(97 \%)$ & 0.73 \\
\hline ACEI & $25(78 \%)$ & $56(65 \%)$ & 0.23 \\
\hline Aspirin & $32(100 \%)$ & $86(100 \%)$ & 1.0 \\
\hline Clopidogrel I month after stenting (N, \%) & $32(100 \%)$ & $86(100 \%)$ & 1.0 \\
\hline$\beta$-blockers ( $\mathrm{N}, \%)$ & $22(69 \%)$ & $48(56 \%)$ & 0.25 \\
\hline Calcium channel blockers (N, \%) & $7(22 \%)$ & $15(17 \%)$ & 0.64 \\
\hline $\begin{array}{l}\text { Target lesion classification according to TASC } \\
\text { (femoropopliteal level) (A/B/C/D) }\end{array}$ & $\begin{array}{l}4(13 \%) / 6(19 \%) / \\
\text { II (34\%)/II (34\%) }\end{array}$ & $\begin{array}{c}0(0 \%) / 21(24 \%) / \\
31(36 \%) / 34(40 \%)\end{array}$ & 0.12 \\
\hline Necessity of intervention in BTK arteries (N, \%) & II (34\%) & $0(0 \%)$ & 0.001 \\
\hline $\begin{array}{l}\text { History of endovascular procedures performed } \\
\text { without stent implantation (N, \%) }\end{array}$ & $10(30 \%)$ & $0(0 \%)$ & 0.0001 \\
\hline Number of stents (BMS) $(\mathrm{N})$ & $1.2 \pm 1.1$ & $1.5 \pm 0.5$ & 0.044 \\
\hline Sum of stent lengths [mm] & $239.5 \pm 175$ & $167.8 \pm 91$ & 0.011 \\
\hline TLR & $27(84 \%)$ & $25(29 \%)$ & 0.001 \\
\hline
\end{tabular}

ACEI — angiotensin-converting-enzyme inhibitor; aPTT — partial thromboplastin time; BMS — bare metal stents. Only this type of stent was implanted in the group of patients analysed; BTK — below-the-knee procedure; CAD — coronary artery disease; INR — international normalized ratio for prothrombin time; LDL — low-density lipoprotein; TASC — Trans-Atlantic Inter-Society Consensus; TLR — target lesion revascularization

which had mostly been applied a few years before or on the day of the first endovascular procedure. Such an assumption explains why these patients had worse outcomes for endovascular interventions, probably related to multi-level lesions, including small vessels which are not suitable for any intervention. Such a suggestion is also supported by our data, which showed that the strongest factor reducing this risk of amputation was the use of statins, the most common and effective hypolipidaemic medicine (Tab. 2). Our observation corroborates reports by other authors who found that optimal medical treatment had a significant influence on the outcome of endovascular therapy $[2,3,10,1 \mathrm{I}]$, and statins helped to salvage limbs after percutaneous intervention [17-25]. Only Dosluoglu et al. [26] were unable to confirm a favourable statins effect on limb salvage. In the context of the above-mentioned data, the significant negative effect of blood LDL cholesterol 
Table 2. Cox's proportional hazards regression for leg amputation risk $\left(\mathrm{Chi}^{2}=127.75 ; \mathrm{p}<0.0000 \mathrm{I}\right)$

\begin{tabular}{|c|c|c|c|c|}
\hline Parameter & $\beta$ & St. error for $\beta$ & $\mathrm{p}$ & Hazard ratio $\pm 95 \% \mathrm{Cl}$ \\
\hline Rutherford class (IV-VI) & 1.33 & 0.31 & $<0.001$ & $3.78 \pm 2.06-6.94$ \\
\hline Number of previous endovascular procedures & -0.93 & 0.37 & 0.012 & $0.40 \pm 0.19-0.82$ \\
\hline Age (years) & 0.02 & 0.042 & 0.59 & $1.02 \pm 0.94-1.11$ \\
\hline Female gender & 2.49 & 0.72 & 0.001 & $12.08 \pm 2.97-49.08$ \\
\hline CAD & -1.15 & 0.73 & 0.11 & $0.32 \pm 0.08-1.3$ \\
\hline $\mathrm{CHF}$ & -0.25 & 0.74 & 0.74 & $0.78 \pm 0.18-3.3$ \\
\hline Atrial fibrillation & -1.08 & 1.07 & 0.31 & $0.34 \pm 0.04-2.76$ \\
\hline History of stroke & -0.85 & 0.94 & 0.37 & $0.43 \pm 0.07-2.71$ \\
\hline Hypertension & -1.67 & 1.08 & 0.12 & $0.19 \pm 0.02-1.55$ \\
\hline Smoking habit & 1.49 & 0.63 & 0.017 & $4.43 \pm 1.29-15.11$ \\
\hline Diabetes mellitus & -0.15 & 0.58 & 0.79 & $0.86 \pm 0.27-2.68$ \\
\hline Dyslipidaemia & 4.07 & 1.03 & 0.0001 & $58.65 \pm 7.78-442.25$ \\
\hline LDL cholesterol [mg/dL] & -0.03 & 0.011 & 0.01 & $0.97 \pm 0.95-0.99$ \\
\hline Triglycerides $[\mathrm{mg} / \mathrm{dL}]$ & 0.003 & 0.006 & 0.65 & $1.00 \pm 0.99-1.102$ \\
\hline Blood glucose $[\mathrm{mg} / \mathrm{dL}]$ & 0.01 & 0.006 & 0.09 & $1.01 \pm 0.99-1.02$ \\
\hline Haemoglobin $[g / L]$ & -0.20 & 0.17 & 0.25 & $0.82 \pm 0.59-1.15$ \\
\hline Leukocyte count $[\mathrm{G} / \mathrm{L}]$ & 0.21 & 0.061 & 0.001 & $1.23 \pm 1.09-1.39$ \\
\hline Platelets [G/L] & -0.002 & 0.003 & 0.46 & $0.99 \pm 0.99-1.00$ \\
\hline $\operatorname{MPV}[\mathrm{fL}]$ & -0.02 & 0.02 & 0.45 & $0.98 \pm 0.94-1.03$ \\
\hline INR & 0.91 & 1.49 & 0.54 & $2.49 \pm 0.13-46.52$ \\
\hline Creatinine $[\mathrm{mg} / \mathrm{dL}]$ & 1.96 & 0.54 & 0.0003 & $7.08 \pm 2.45-20.50$ \\
\hline $\begin{array}{l}\text { Target lesion classification according to TASC } \\
\text { (femoropopliteal level) (A/B/C/D/BTK) }\end{array}$ & -0.05 & 0.40 & 0.90 & $0.95 \pm 0.44-2.08$ \\
\hline Number of patent BTK vessels $(N)$ & 1.48 & 0.97 & 0.13 & $4.40 \pm 0.66-29.2$ \\
\hline Number of patent vessels on foot $(\mathrm{N})$ & -0.94 & 0.64 & 0.14 & $0.39 \pm 0.11-1.37$ \\
\hline Statins use $(\mathrm{N})$ & -2.61 & 0.89 & 0.003 & $0.07 \pm 0.1-0.42$ \\
\hline Use of calcium channel blocker & -1.18 & 0.89 & 0.19 & $0.31 \pm 0.05-1.77$ \\
\hline Use of $\beta$-blocker & 0.13 & 0.81 & 0.87 & $1.14 \pm 0.24-5.52$ \\
\hline Number of implanted stent in analysed period & -0.83 & 0.46 & 0.07 & $0.44 \pm 0.18-1.07$ \\
\hline Sum of implanted stent lengths & 0.004 & 0.003 & 0.18 & $1.00 \pm 0.99-1.01$ \\
\hline TLR & 1.93 & 0.66 & 0.004 & $6.92 \pm 1.88-25.48$ \\
\hline
\end{tabular}

BTK — below-the-knee procedure; CAD — coronary artery disease; CHF — congestive heart failure; $\mathrm{Cl}$ — confidence interval; INR — international normalized ratio for prothrombin time; LDL — low-density lipoprotein; MPV — mean platelet volume; TASC — Trans-Atlantic Inter-Society Consensus; TLR — target lesion revascularization

level on the risk of amputation seems to be strange (Tab. 2). However, this effect was relatively weak(HR0.97), which, in our opinion, supports the hypothesis that a low cholesterol level in patients with a leg amputation should be recognized, not as an atherosclerosis risk factor, but as a marker of the general severity of a patient's malnutrition status [27].

We also found a strong effect of female gender (HR of about I2), blood creatinine (HR of about 7), and smoking habit (HR of about 4) on the risk of leg amputation (Tab. 2). Worse outcomes for endovascular intervention and a greater risk of leg amputation among individuals with chronic kidney disease $[1,28]$ and in patients with an uncontrolled atherosclerosis risk factor $[1-3,8-10,25]$ have previously been reported. However, in recent studies by Hedayati et al. [29] and Lo et al. [30], women were more likely than men to have CLI (in our study, only $21 \%$ of the patients were female, Tab. I), but they had a similar I 2-month reintervention rate, and better amputation-free survival. Whereas, in the study by Vierthaler and the members of the Vascular Study Group of New England [7], among other 


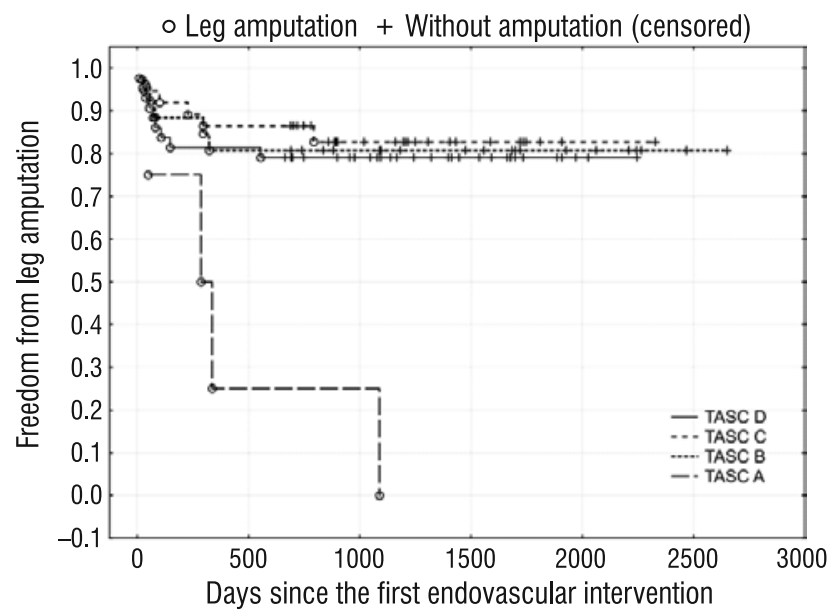

Figure 2. Kaplan-Meier curve showing the risk of leg amputation in relation to angiographic lesion severity according to TASC classification at the femoropopliteal vascular level

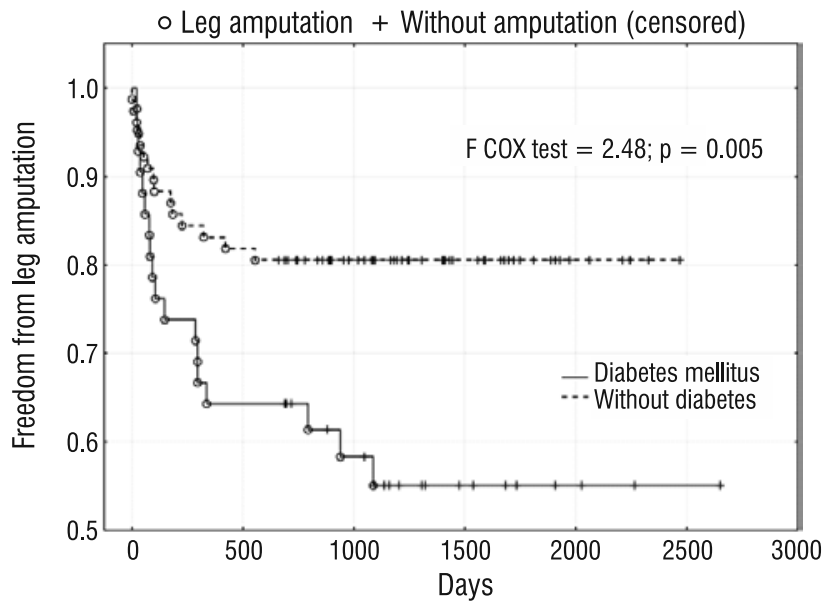

Figure 3. Kaplan-Meier curve showing the risk of amputation among diabetic and non-diabetic patients

factors, male gender (HR I.6) increased the risk of leg amputation, and smoking (HR 0.60 ) was protective. However, according to the study by Selvarajah et al. [3I] and widely accepted knowledge $[1-3,9]$, active smokers had an increased risk of LLI progression and the failure of its treatment, pharmacologically, endovascularly and surgically.

Our analysis showed the favourable effect of consecutive endovascular procedures on amputation delay, but also revealed that loss of primary stent patency (expressed by the need for TLR) or the absence of stent implantation led to worse outcomes (Tab. I, 2). At the same time, we did not confirm an effect of angiographic lesion severity according to the
TASC classification and our own runoff score for crus and foot on amputation-free survival (Tab. 2, Fig. 2). However, such observations are consistent with other authors' reports, because the main factors affecting the outcome of endovascular interventions in patients with CLI were: severity of tissue loss, comorbidities and medication [3, 32].

In our study, we also analysed the effect of cardiovascular medicines on limb salvage and amputation-free survival (Tab. I, 2). However, we could only confirm the above-mentioned favourable effect of statins use. The importance of optimal medical treatment on patients with CLI is emphasized in another paper [3]. The favourable effect of cilostazol on patients with LLI following endovascular treatment has also been reported [33].

Although our study showed statistically significant relationships between risk of leg amputation and a number of clinical factors, we could not avoid some methodological shortcomings that could have limited the strength of the deductions based on our results. First, our study was performed according to a retrospective study design with a relatively small group of patients. These factors make our multivariate analysis less reliable, and render it impossible to propose a risk stratification scale for further discussion and eventual validation.

\section{Conclusions}

The risk of major amputation following endovascular treatment in patients with CLI was associated with a number of patient characteristics, mainly: dyslipidaemia, gender, blood creatinine, smoking habit, medication, and the need for reintervention. For the purpose of limb salvage, patients with CLI need management of traditional atherosclerosis risk factors after endovascular treatment, as well as clinical and ultrasonographic surveillance in order to perform reinterventions with artery stenting which may extend amputation-free survival. As a result of the high risk of amputation in patients with $\mathrm{CLI}$ and the frequent need for re-intervention, large studies are needed to prepare a risk stratification scoring system for these patients, which, after further validation, could enable risk-adjusted patients to qualify for endovascular or surgical revascularization or for primary leg amputation. Such a scale could help to avoid endangering patients and the unnecessary utilization of resources.

\section{References}

I. Norgren L, Hiatt WR, Dormandy JA et al (2007) Inter-Society Consensus for the Management of Peripheral Arterial Disease (TASC II). Eur J Vasc Endovasc Surg; 33 Suppl I: SI-S75. 
2. Perk J, De Backer G, Gohlke H et al (2012) European Guidelines on cardiovascular disease prevention in clinical practice (version 20I2). The Fifth Joint Task Force of the European Society of Cardiology and Other Societies on Cardiovascular Disease Prevention in Clinical Practice (constituted by representatives of nine societies and by invited experts). Eur Heart J; 33: 1635-1701.

3. Chung J, Timaran DA, Modrall JG et al (2013) Optimal medical therapy predicts amputation-free survival in chronic critical limb ischemia. J Vasc Surg; 58: 972-980.

4. Kay M, Rogoveanu R, Hodson J et al (2015) Factors Affecting the Results of Superficial Femoral Artery Stenting. Vasc Endovascular Surg; 49: 228-235.

5. Soga Y, lida O, Takahara M et al (2014) Two-year life expectancy in patients with critical limb ischemia. JACC Cardiovasc Interv; 7: 1444-1449.

6. Yost ML. The cost of amputation in 2014. Lecture presented at the $4^{\text {th }}$ annual Amputation Prevention Symposium. August 14-16, 2014, Palmer House Hilton. Chicago IL.

7. Vierthaler L, Callas PW, Goodney PP et al (2015) Determinants of survival and major amputation after peripheral endovascular intervention for critical limb ischemia. J Vasc Surg; 62: 655-664.

8. TASC Steering Committee, Jaff MR, White CJ et al (2015) An Update on Methods for Revascularization and Expansion of the TASC Lesion Classification to Include Below-the-Knee Arteries: A Supplement to the Inter-Society Consensus for the Management of Peripheral Arterial Disease (TASC II). J Endovasc Ther; 22: 663-677.

9. European Stroke Organisation, Tendera $M$, Aboyans $V$ et al (20I I) ESC Committee for Practice Guidelines. ESC Guidelines on the diagnosis and treatment of peripheral artery diseases: document covering atherosclerotic disease of extracranial carotid and vertebral. mesenteric. renal. upper and lower extremity arteries: the Task Force on the Diagnosis and Treatment of Peripheral Artery Diseases of the European Society of Cardiology (ESC). Eur Heart J; 32: 285I-2906.

10. Armstrong EJ, Chen DC, Westin GG et al (2014) Adherence to guideline-recommended therapy is associated with decreased major adverse cardiovascular events and major adverse limb events among patients with peripheral arterial disease. J Am Heart Assoc; 3: e000697.

II. Poredoš P, Jezovnik MK, Kalodiki E et al (2015) Medical management of patients with peripheral arterial disease. Int Angiol; 34: 75-93.

12. Diehm N, Baumgartner I, Jaff M et al (2007) A call for uniform reporting standards in studies assessing endovascular treatment for chronic ischaemia of lower limb arteries. Eur Heart J; 28: 798-805.

13. May KK, Robless PA, Sidhu HR et al (2014) Limb salvage in patients with peripheral arterial disease managed by endovascular first approach. Vasc Endovascular Surg; 48: 129-133.

14. Garg K, Kaszubski PA, Moridzadeh R et al (2014) Endovascular-first approach is not associated with worse amputation-free survival in appropriately selected patients with critical limb ischemia. J Vasc Surg; 59: 392-399.

15. Chrysant SG (20II) A new paradigm in the treatment of the cardiovascular disease continuum: focus on prevention. Hippokratia; 15: 7-II.

16. Pollak AW (2015) PAD in women: the ischemic continuum. Curr Atheroscler Rep; 17: 513.

17. Jones WS, Patel MR, Tsai TT et al (2015) Anatomic runoff score predicts cardiovascular outcomes in patients with lower ex- tremity peripheral artery disease undergoing revascularization. Am Heart J; 170: 400-408.

18. Aiello FA, Khan AA, Meltzer AJ et al (2012) Statin therapy is associated with superior clinical outcomes after endovascular treatment of critical limb ischemia. J Vasc Surg; 55: 37I-379.

19. Antoniou GA, Fisher RK, Georgiadis GS et al (2014) Statin therapy in lower limb peripheral arterial disease: systematic review and meta-analysis. Vascul Pharmacol; 63: 79-87.

20. Erez G, Leitersdorf E (2007) The rationale for using HMG-CoA reductase inhibitors ('statins') in peripheral arterial disease. Eur J Vasc Endovasc Surg; 33: 192-201.

21. Kumbhani DJ, Steg PG, Cannon CP, et al (2014). Statin therapy and long-term adverse limb outcomes in patients with peripheral artery disease: insights from the REACH registry. Eur Heart J; 35: 2864-2872.

22. Suckow BD, Kraiss LW, Schanzer A et al (2015) Statin therapy after infrainguinal bypass surgery for critical limb ischemia is associated with improved 5-year survival. J Vasc Surg; 61: 126-133.

23. Tomoi Y, Soga $Y$, lida $O$ et al (2013) Efficacy of statin treatment after endovascular therapy for isolated below-the-knee disease in patients with critical limb ischemia. Cardiovasc Interv Ther; 28: 374-382.

24. Vogel TR, Dombrovskiy VY, Galiñanes EL et al (2013) Preoperative statins and limb salvage after lower extremity revascularization in the Medicare population. Circ Cardiovasc Interv; 6: 694-700.

25. Westin GG, Armstrong EJ, Bang $\mathrm{H}$ et al (2014) Association between statin medications and mortality. major adverse cardiovascular event. and amputation-free survival in patients with critical limb ischemia. J Am Coll Cardiol; 63: 682-690.

26. Dosluoglu HH, Davari-Farid S, Pourafkari L et al (2012) Statin use is associated with improved overall survival without affecting patency and limb salvage rates following open or endovascular revascularization. Vasc Med; 19: 86-93.

27. Owens CD, Kim JM, Hevelone ND et al (20/2) An integrated biochemical prediction model of all-cause mortality in patients undergoing lower extremity bypass surgery for advanced peripheral artery disease. J Vasc Surg; 56: 686-695.

28. Silverberg D, Yalon T, Rimon $U$ et al (2013) Endovascular treatment of lower extremity ischemia in chronic renal failure patients on dialysis: early and intermediate term results. Isr Med Assoc J; 15: 734-738.

29. Hedayati N, Brunson A, Li CS et al (2015) Do Women Have Worse Amputation-Free Survival Than Men Following Endovacular Procedures for Peripheral Arterial Disease? An Evaluation of the California State-Wide Database. Vasc Endovascular Surg; 49: 166-174.

30. Lo RC, Bensley RP, Dahlberg SE et al (2014) Presentation, treatment, and outcome differences between men and women undergoing revascularization or amputation for lower extremity peripheral arterial disease. J Vasc Surg; 59: 409-4I8.

31. Selvarajah S, Black JH $3^{\text {rd }}$, Malas MB et al (2014) Preoperative smoking is associated with early graft failure after infrainguinal bypass surgery. J Vasc Surg; 59: 1308-1314.

32. Meltzer AJ, Evangelisti G, Graham AR et al (2014) Determinants of outcome after endovascular therapy for critical limb ischemia with tissue loss. Ann Vasc Surg; 28: 144-151.

33. Neel JD, Kruse RL, Dombrovskiy VY et al (2015) Cilostazol and freedom from amputation after lower extremity revascularization. J Vasc Surg; 61: 960-964. 